\title{
The association between nutritional and functional status in patients undergoing endovascular intervention due to chronic lower limbs ischemia
}

\author{
Corresponding author: \\ Jacek Budzyński, Department \\ of Vascular and Internal Diseases, \\ Faculty of Health Sciences, \\ Ludwik Rydygier Collegium Medicum \\ in Bydgoszcz, Nicolaus Copernicus \\ University in Toruń, Poland; \\ e-mail: budz@cps.p
}

Medical Research Journal 2018; Volume 3, Number 2, 55-62 10.5603/MRJ.2018.0010

Copyright (C) 2018 Via Medica ISSN 2451-2591

\begin{abstract}
Background: The nutritional status and functional status of patients are important prognostic factors. The aim of the study was to assess the relationships between patients' nutritional status and the outcome of endovascular intervention in patients with chronic lower limb ischemia during one-year follow-up. Materials and methods: In 79 consecutive patients subjected to endovascular intervention due to chronic leg ischemia following examinations were performed before and after 3 and 12 month after surgery: physical examination, Minimal Nutritional Assessment (MNA) score, Nutritional Risk Screening 2002 score (NRS2002), Barthel, ADL, IADL scale, ankle-brachial index (ABI), claudication distance on the treadmill and handgrip strength.

Results: More than half of patients were initially overweight or obese. Following 3 months after the surgery, improvement in lower limb symptoms was observed, together with significant increase in $\mathrm{ABI}$, claudication distance, total MNA score and IADL scale. The risk associated with malnutrition (MNA questionnaire), Barthel score and hand grip strength showed a statistically significant relationship with the subjective feeling of improvement after surgery. Its absence was more frequent in patients characterized by higher risk of malnutrition, with less muscular strength and poorer fitness.

Conclusions: Endovascular treatment of lower limbs ischemia improved not only symptoms of leg ischemia but also the general functional status of patients. The initial nutritional status, functional status and hand grip strength of patients with chronic lower limb ischemia were associated with a better clinical outcome of endovascular intervention.

Key words: nutritional status, functional status, lower limbs ischemia, revascularization, endovascular treatment
\end{abstract}

Med Res J 2018; 3 (2): 55-62

\section{Introduction}

Nutritional status is one of the most important determinants of the health condition of a patient requiring hospitalization. Recent reports indicate that the relationship between in-hospital mortality and the body mass index (BMI) values forms the U-shaped curve [1]. The increase in the in-hospital mortality in patients with low body mass (left arm of the curve) is relatively easy to explain. It usually results from the final stage of chronic and wasting diseases [1]. Therefore, the course of the right arm of the U-shaped curve draws more attention, as it concerns patients with a better prognosis. Many studies indicate that it is shifted to the right side, far beyond the BMI WHO's ranges regarded as correct ones [1-9]. This effect is often referred to as the "obesity paradox" and consists in a better prognosis of overweight patients and mildly obese patients as compared to patients with normal body weight and with similar severity of atherosclerosis of the lower limbs [10].

The nutritional status of patients and the risk associated with the nutritional status are assessed on the basis of: (a) a nutritional history, sometimes generated in the form of validated questionnaires (NRS-2002; Subjective Global Assessment, SGA; Malnutrition Universal Screening Tool, MUST; Mini-Nutritional Assessment, 
MNA) [4]; (b) physical examination including anthropometric measurements (height, weight, BMI, abdominal circumference, arm circumference, thickness of skin folds); (c) body composition analysis (bioelectric impedance, BIA, dual energy x-ray absorptiometry, DXA, computed tomography, CT, magnetic resonance, MR); (d) biochemical markers of malnutrition (albumin, cholesterol, hemoglobin, transferrin and leptin concentration albumin, absolute lymphocyte count in blood); and (e) complex clinical and biochemical indicators of nutrition, mainly based on history, measurements of current and ideal body weight, and results of biochemical tests (e.g. nutritional risk index NRI; geriatric nutritional index, GNRI; instant nutritional assessment, INA; Prognostic Nutritional Index, PNI; prognostic inflammation and nutritional index, PINI; Onodera's (Preoperative) Prognostic Nutritional Index, OPNI [4]. An important and recently appreciated indicator for assessment of the patient's nutritional status is the determination of the amount of muscle tissue, or more precisely its deficiency, called sarcopenia [11-15]. It is known that a patient with sarcopenia is characterized by a worse prognosis, even when his or her nutritional status is excessive (sarcopenic obesity) [11-15]. The severity of sarcopenia is assessed on the basis of: (a) measurement of human body muscle mass (anthropometric measurements, e.g. arm muscle circumference, arm muscle surface area, shin circumference, body composition analysis) [11-12], (b) fitness and functional status of a patient (gait speed, step swing speed, and in the nursing practice - using the Barthel, ADL or IADL scale); [12] and (c) the strength of the hand grip measured with the dynamometer [11].

The aim of the study was to assess the relations between clinical advancement of chronic ischemia of lower limbs and the nutritional and functional status of patients treated endovascularly due to chronic lower limb ischemia in a one-year of follow-up.

\section{Material and methods}

\section{Subjects}

Seventy nine consecutive patients subjected to endovascular intervention due to chronic ischemia of the lower limbs were examined in the study. The inclusion criteria were as follows: (a) symptoms of chronic lower limb ischemia sub-form of intermittent claudication (Cl), defined as lower limb pain after walking of a specific distance, the length of which was limited by daily activity of a patient) and a decrease in the ankle-brachial index $\mathrm{ABI}<0.9$ or sub-form of critical limb ischemia (CLI), corresponding to 4-6 class of severity of symptoms according to Rutherford (resting pain of the lower limbs, mitigated by putting a lower limb down, with or without lesser or greater necrosis of a foot) with the coexistence of a decrease in $\mathrm{ABI}<0.4$; (b) consent to participate in the study. While the exclusion criteria were as follows: (a) acute limb ischemia, (b) qualification for primary amputation, (c) no consent to participate in the study.

\section{Methods}

Each patient's medical history was taken in the form of a research questionnaire, assessing the nutritional status by means of the Minimal Nutritional Assessment (MNA) and Nutritional Risk Screening 2002 (NRS2002) questionnaires, and the patient's functional status was assessed using Barthel, ADL and IADL questionnaires, the physical examination was performed as well as the value of the ankle-brachial index (ABI), the distance of claudication on the treadmill in the standard protocol $\left(3.2 \mathrm{~km} / \mathrm{h}\right.$, slope of $\left.12^{\circ}\right)$ and the handgrip strength of both hands was assessed using the KERN dynamometer. The clinical grade of lower limb ischemia was assessed according to the Rutherford classification.

Each patient underwent at least one-year follow-up and follow-up visits were arranged 3 and 12 months after surgery. During a follow-up visit, handgrip strength, claudication distance, functional status on the above-mentioned functional scales and the occurrence of measured endpoints were assessed.

\section{Measured end-points}

The values of the parameters subject to evaluation were the measured end-points for the analysis of the output data. However, in the annual follow-up after the first hospitalization, the following end-points were assessed: death regardless of the cause, death caused by cardiovascular failure, stroke, need for rehospitalization, number of rehospitalizations, subjective improvement after surgery, loss of self-care ability, score in the MNA questionnaire, on the Barthel, IADI and ADL scale.

\section{Bioethics committee}

The study has been carried out on the basis of the consent No. KB 643/2015 of the local Bioethics Committee. The study has been performed in line with the amended Declaration of Helsinki. Each patient expressed in writing his/her consent to participate in the study.

\section{Statistical analysis}

The statistical analysis was performed using the licensed 13 version of Dell STATISTICA 13.0 (Dell Incl., USA.) software. The distribution of variables was examined using the Shapiro-Wilk W test. The results are presented as a mean \pm standard deviation and abun- 
dance in subgroups of patients with a given feature and percentage of the entire cohort. Statistical significance of the average difference between subgroups was evaluated using the Student's t test and the Chi-squared test. The differences for $p<0.05$ were deemed statistically significant. The statistical significance of particular variables in the multivariate analysis was determined by means of logistic regression and proportional hazards model (Cox model) in the survival analysis module.

\section{Results}

The groups of patients divided according to the severity of lower limb ischemia into those with critical ischemia (CLI) and intermittent claudication (IC) did not differed in relation to the values of clinical variables examined (demographic data, atherosclerosis risk factors, score in nutritional questionnaires, anthropometric parameters of the nutritional status, hand grip strength and score on functional status assessment scales) besides values of variables being a diagnostic criteria for IC and CLI, such as ABI and walking distance (Tab. 1). More than half of the analyzed patients were overweight or obese (Tab. 1). The value of BMI did not discriminate patients with a respective clinical grade of leg ischemia (Tab. 1). As revealed by the assessment on the second day after the surgery, the revascularization of the lower limbs resulted in a hemodynamic and clinical benefit in over $80 \%$ of the treated patients, which was reflected, among others, in the increase in $A B I$ value and the distance of claudication (Tab. 1). After 3 months, 35\% and $23 \%$ of treated patients with CLI and IC reported worsening of symptoms, respectively; however, none of them required further surgery or amputation.

The risk associated with malnutrition was determined using the NRS2002 and MNA questionnaire. After 3 months following the surgery, a significant increase was observed in the total MNA score (Fig. 1), as regards the first and second part of the questionnaire and $B$ module, which suggested a decrease in the risk of malnutrition. However, both initial MNA score and determined at 3 month after intervention were placed in the score range showing lack of nutritionrelated risk (24-30 score). There was a statistically significant relationship between the score of the MNA questionnaire and the vascular segment affected by the revascularization procedure. The lowest score, and therefore the greatest risk associated with the nutritional status, was observed in patients requiring revascularization at the below the knee (BTK) segment (Fig. 2). Patients requiring BTK revascularization had also the lowest average handgrip strength during the one-year follow-up (Fig. 3). However, the highest muscle strength before the surgery was presented by patients who reported a subjective improvement in the pain of lower limbs after revascularization, while the patients with worsening in limb pain intensity after revascularization had the least handgrip strength (Fig. 3). The strength of a grip of the dominant hand before the revascularization procedure in the examined patients was also associated with: (a) cigarette smoking, (b) need of rehospitalization within 3 and 12 months after surgery (e.g., readmitted vs. non-hospitalized patients within 12 months $=24.7 \pm 12.1 \mathrm{~kg}$ vs. $40.0 \pm 11.7 \mathrm{~kg}$, $\mathrm{p}=0.008$ ), and (c) the clinical severity of lower limb ischemia before surgery (decreased in an inversely proportional way to the score on Rutherford scale; $R=-0.22, p=0.043)$. At the 3-month visit after the revascularization of the lower limbs, the functional status of the patients, determined using the IADL scale, also significantly improved (Fig. 3). The changes measured using Barthel and ADL scale were not significant.

Statistically significant correlations were demonstrated between the right hand grip strength measured by the dynamometer and the total score in the MNA questionnaire $(r=0.22, p<0.05)$, the score on the Barthel scale $(r=0.25, p<0.05)$, amplitude of $A B I$ value $(R=0.32, p=0.005)$ and absolute walking distance $(R=0.31 ; p=0.006)$ after intervention. The value of the initial Barthel score also correlated with the subjective assessment of surgery effect (improvement, no-effect, worsening; $r=0.32, p<0.05$ ), so patients who declared improvement after surgery were initially more functionally fit and patients with a lower degree of fitness more often felt no improvement after the surgery, and sometimes even reported worsening. On the other hand, the score for the Barthel scale was negatively correlated with the clinical severity of lower limb ischemia on the Rutherford scale $(r=-0.26$, $p<0.05)$. Multivariate analysis based on the Cox logistic regression and proportional hazards method did not determine statistically significant variables of predictive value for the occurrence of measured endpoints (data not shown in detail).

\section{Discussion}

In this study, the authors performed the analysis of the relations between symptoms severity of chronic lower limbs ischemia and the nutritional and functional status of patients undergoing endovascular leg revascularization due to IC and CLI. The lower limb revascularization procedure, in addition to statistically significant lengthening the claudication distance and increasing the ankle-brachial index (Tab. 1), also improved a patient's general functional status expressed as the IADL score (Fig.4) and nutritional risk of a patient expressed by the MNA questionnaire score (Fig. 1). However, the 
Table 1. Clinical characteristics of patients with critical lower limb ischemia and with intermittent claudication

\begin{tabular}{|c|c|c|c|}
\hline Parameter & $\begin{array}{l}\text { Critical chronic } \\
\text { leg ischemia }(n=28)\end{array}$ & $\begin{array}{l}\text { Intermittent } \\
\text { claudication }(n=51)\end{array}$ & $\mathbf{p}$ \\
\hline Age (years) & $64.25 \pm 7.90$ & $61.35 \pm 6.91$ & 0.09 \\
\hline Sex (male gender, $\mathrm{n}, \%$ ) & $22(78.6 \%)$ & $36(70.6 \%)$ & 0.23 \\
\hline BMl (kg/m2) & $26.33 \pm 4.36$ & $26.25 \pm 5.09$ & 0.95 \\
\hline BMI (normal, overweight, obesity, n, \%) & $\begin{array}{c}12(42.9 \%) \\
10(35.7 \%) \\
6(21.4 \%)\end{array}$ & $\begin{array}{l}19(37.3 \%) \\
17(33.3 \%) \\
13(25.5 \%)\end{array}$ & 0.78 \\
\hline Difference between current and ideal weight (kg) & $11.6 \pm 12.6$ & $12.7 \pm 14.7$ & 0.75 \\
\hline Quotient of the current to ideal weight (\%) & $118.4 \pm 19.9$ & $119.7 \pm 22.7$ & 0.80 \\
\hline Percentage of patients with body mass deficiency (\%) & $5(17.9 \%)$ & $11(21.6 \%)$ & 0.63 \\
\hline Right handgrip strength measured with dynamometer (kg) & $33.73 \pm 10.85$ & $31.93 \pm 13.34$ & 0.54 \\
\hline Left handgrip strength measured with dynamometer $(\mathrm{kg})$ & $31.23 \pm 10.35$ & $30.63 \pm 12.07$ & 0.82 \\
\hline Diabetes (n, \%) & $11(39.3 \%)$ & $18(35.3 \%)$ & 0.54 \\
\hline Arterial hypertension (n, \%) & $22(78.6 \%)$ & $34(66.7 \%)$ & 0.27 \\
\hline Cardiac failure (n, \%) & $4(14.3 \%)$ & $7(13.7 \%)$ & 0.64 \\
\hline History of myocardial infarction (n, \%) & $7(25 \%)$ & $20(39.2 \%)$ & 0.44 \\
\hline History of TIA/stroke (n, \%) & $3(10.7 \%)$ & $5(9.8 \%)$ & 0.44 \\
\hline smoking of cigarettes (ex-/ current smoker) & $\begin{array}{l}15(53.6 \%) \\
11(39.3 \%)\end{array}$ & $\begin{array}{l}27(52.9 \%) \\
23(45.1 \%)\end{array}$ & 0.10 \\
\hline$A B I$ of right limb before surgery & $0.48 \pm 0.39$ & $0.64 \pm 0.19$ & 0.01 \\
\hline$A B I$ of left limb before surgery & $0.35 \pm 0.32$ & $0.61 \pm 0.19$ & $<0.001$ \\
\hline$A B I$ after the surgery on the treated limb & $0.64 \pm 0.29$ & $0.86 \pm 0.20$ & $<0.001$ \\
\hline$A B I$ increase after surgery $>0.15$ & $23(82.1 \%)$ & $44(86.3 \%)$ & 0.99 \\
\hline Walk test before intervention (m) & $54.46 \pm 33.98$ & $105.20 \pm 56.3$ & $<0.001$ \\
\hline Walk test after surgery (m) & $204.04 \pm 103.96$ & $291.20 \pm 90.29$ & $<0.001$ \\
\hline Rutherford classification (3/4/5), n, \% & $\begin{array}{c}0 \\
17(60.7 \%) \\
11(39.3 \%)\end{array}$ & $\begin{array}{c}51(100 \%) \\
0 \\
0\end{array}$ & $<0.001$ \\
\hline MNA total score (maximally 30 points) & $25.54 \pm 2.16$ & $25.75 \pm 2.49$ & 0.71 \\
\hline MNA part 1 (maximally 14 points) & $12.57 \pm 1.60$ & $12.71 \pm 1.64$ & 0.73 \\
\hline MNA part 2 (maximally 16 points) & $12.96 \pm 1.18$ & $13.02 \pm 1.20$ & 0.84 \\
\hline Barthel scale (maximally 100 points) & $98.04 \pm 8.54$ & $98.92 \pm 4.72$ & 0.55 \\
\hline ADL scale (maximally 7 points) & $5.96 \pm 0.19$ & $5.94 \pm 0.31$ & 0.72 \\
\hline IADL scale (maximally 24 points) & $22.11 \pm 2.47$ & $22.82 \pm 1.92$ & 0.16 \\
\hline $\begin{array}{l}\text { Treated vascular segment (aortic and iliac / femoro-popliteal } \\
\text { segment / below the knee) }\end{array}$ & $\begin{array}{c}6(21.4 \%) \\
16(57.2 \%) \\
6(21.4 \%)\end{array}$ & $\begin{array}{c}19(37.3 \%) \\
32(62.7 \%) \\
0\end{array}$ & 0.42 \\
\hline $\begin{array}{l}\text { The effect of the surgery after } 3 \text { months (improvement / no } \\
\text { improvement / deterioration, } n, \%)\end{array}$ & $\begin{array}{c}13(46.4 \%) \\
5(17.9 \%) \\
10(35.7 \%)\end{array}$ & $\begin{array}{l}25(49.7 \%) \\
14(27.7 \%) \\
12(23.6 \%)\end{array}$ & 0.57 \\
\hline
\end{tabular}

analysis of the segment in which revascularization was performed, showed that this improvement in nutritional status was not observed in patients whose endovascular surgery was performed in BTK arteries (Fig. 2). Better initial nutritional status, greater muscle strength and a higher degree of fitness before vascular intervention were also associated with a subjective assessment of endovascular procedure outcome, and patients who reported no improvement in lower limb discomfort had the smallest average hand grip strength determined 


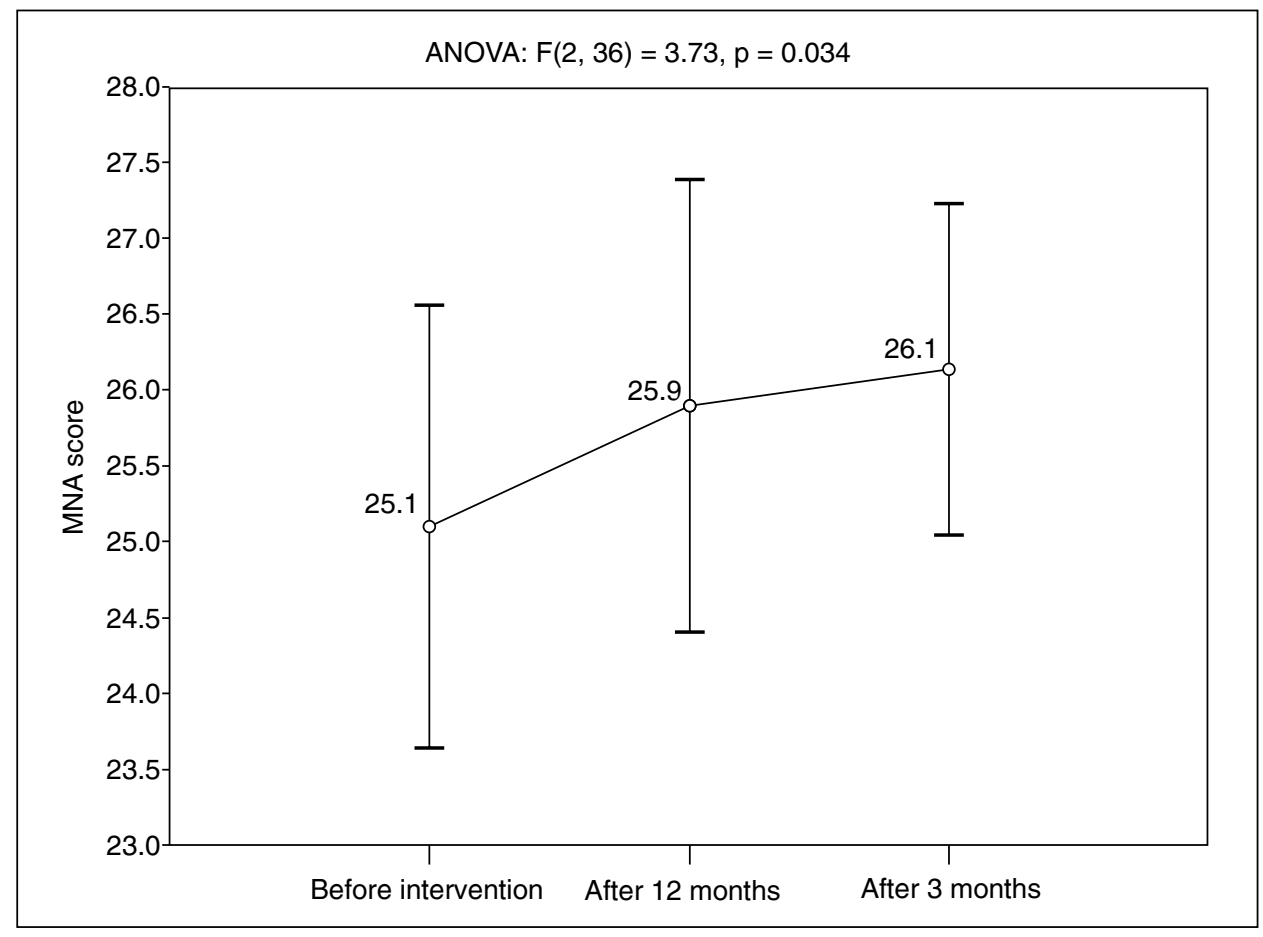

Figure. 1. Scores of the MNA questionnaire obtained before the surgery and on subsequent follow-up visits after revascularization of the lower limbs

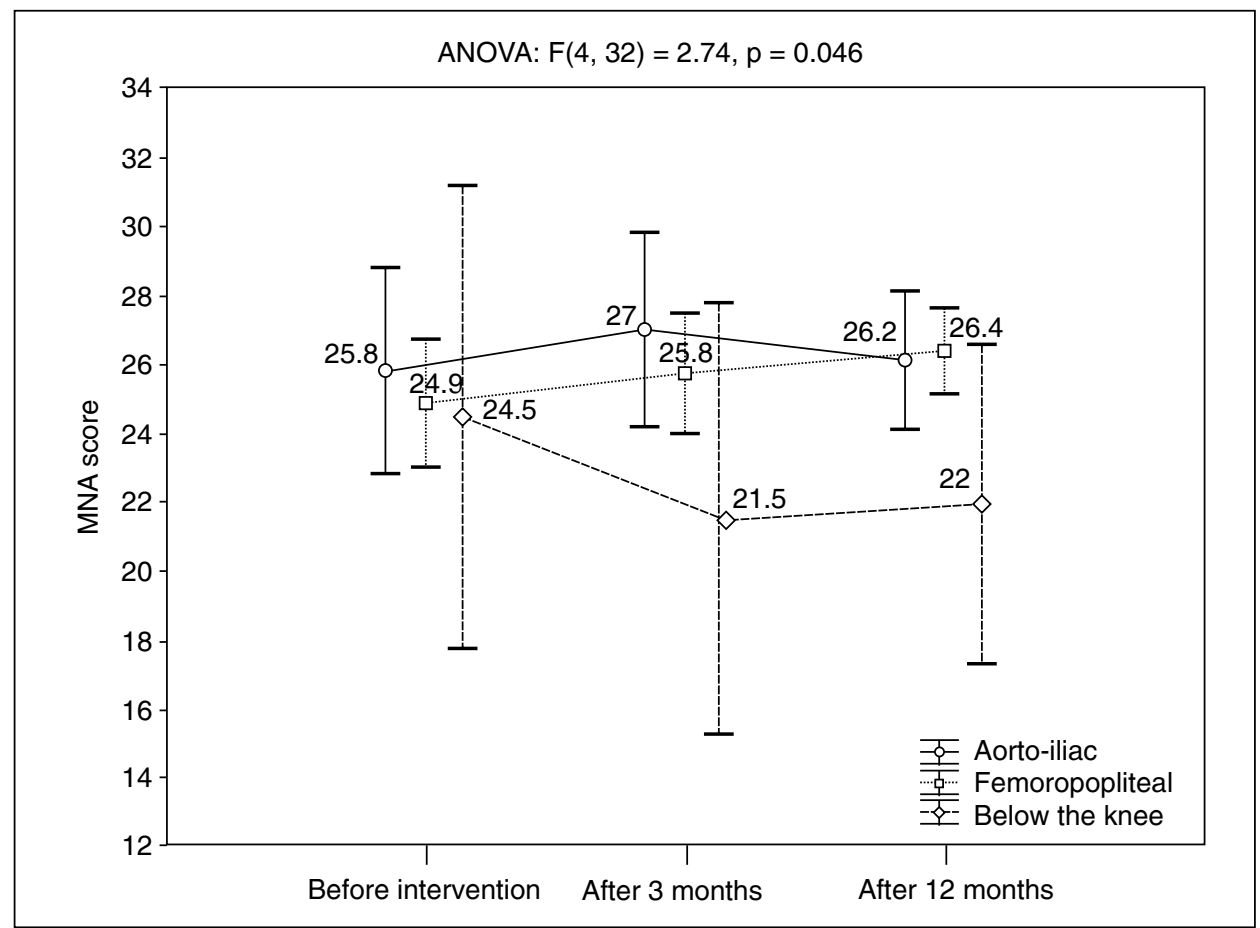

Figure. 2. Scores obtained in the MNA questionnaire before the surgery and on subsequent follow-up visits after revascularization of the lower limbs depending on the vascular segment subjected to the surgery 


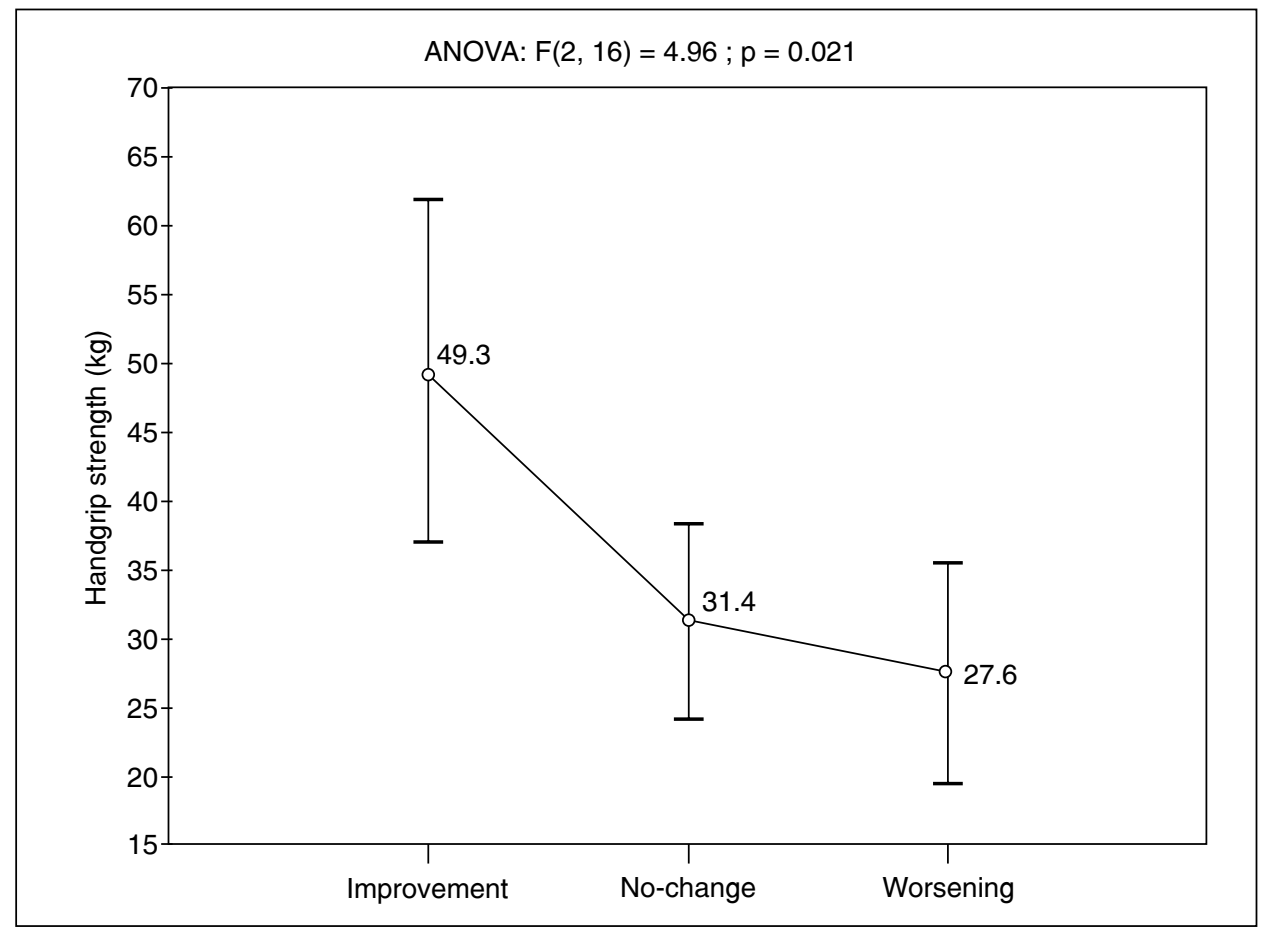

Figure. 3. The average handgrip strength measured on subsequent visits within 12 months of follow-up depending on the subjective assessment of the treatment effect (ANOVA, the main effect)

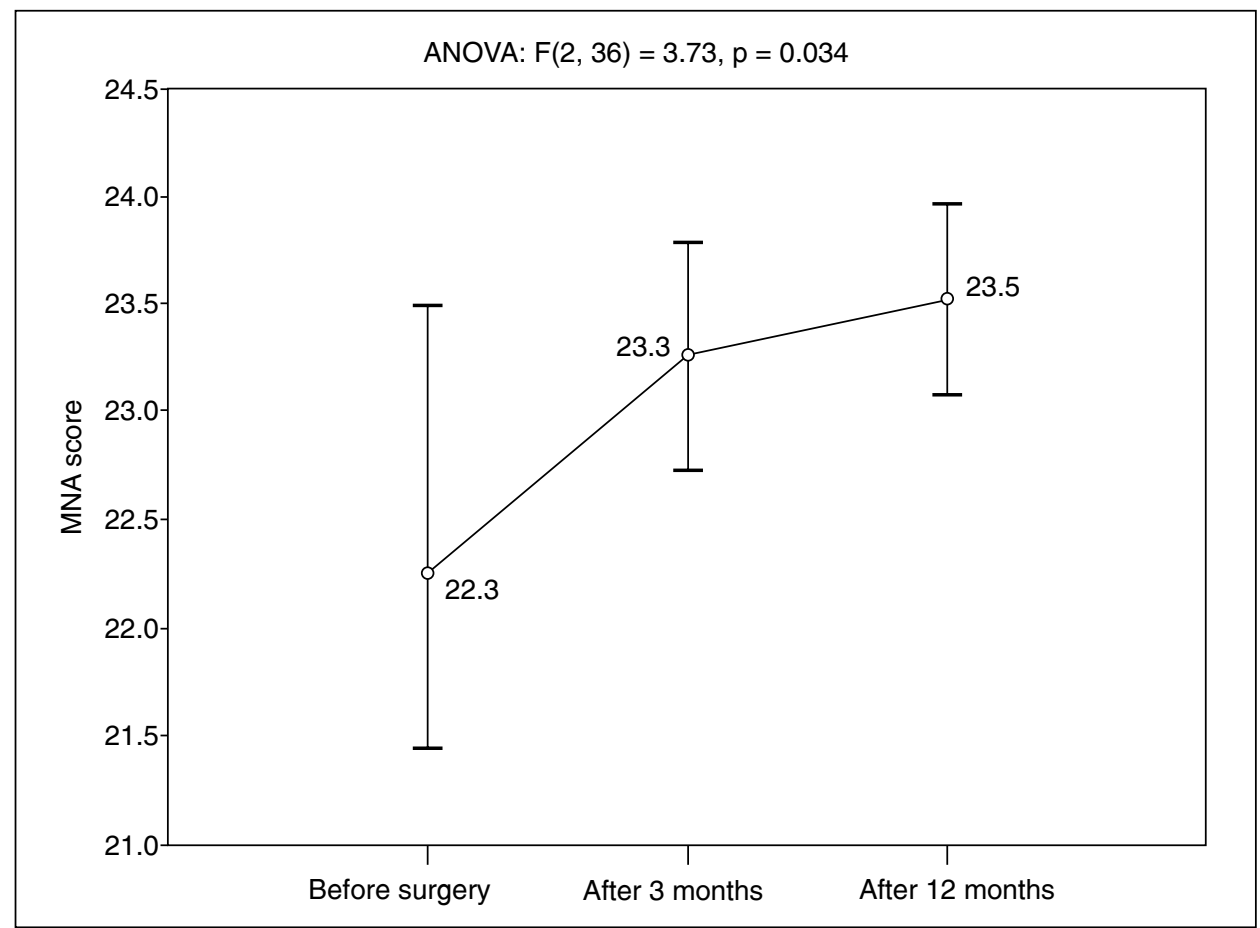

Figure. 4. Scores obtained in the IADL questionnaire for the assessment of patients functional status before the surgery and on subsequent follow-up visits after revascularization of the lower limbs 
during three subsequent follow-up visits (Fig. 3). In the available literature there are no analyses that are similar to the analysis carried out in this study, apart from the work of Landry et al. [16]. However, the results obtained indirectly corroborate with the reports of other authors who indicated to the prognostic significance of patients' nutritional status, determined mainly by the BMI value, as regards the effect of revascularization of the limbs and the occurrence of possible complications [10, 16-21]. It is also known that patients with chronic lower limb ischemia are characterized by impaired fitness [22-28], and supervised walking training and physical activity help reduce the severity of the chronic limb ischemia symptoms [29-32], which allows explaining the demonstrated better prognosis regarding the outcome of revascularization treatment in stronger and more fit patients, like those who have a better chance of earlier returning to full physical activity after the surgery.

The high incidence of overweight and obesity in the study group, expressed in high BMI values (Tab. 1), reflected its prevalence in the general population. According to the WOBASZ 2011-2014 study (Multi-center National Population Health Examination Survey), the prevalence of overweight $\left(<25 \mathrm{~kg} / \mathrm{m}^{2}<\mathrm{BMl}<30 \mathrm{~kg} / \mathrm{m}^{2}\right)$ among the Polish population amounts to $43.2 \%$ in men and $30.5 \%$ in women, and obesity (BMI > $30 \mathrm{~kg} / \mathrm{m}^{2}$ ) prevalence amounts to $24.4 \%$ among men and $25.4 \%$ among woman [33].

Handgrip strength and the score in the MNA questionnaire proved to be factors related to the outcome of endovascular treatment of chronic lower limb ischemia and this problem certainly requires further research on the role of muscle and fatty tissue in the pathogenesis of frailty [34], poor functional status of patients with lower limb ischemia, as well as pathogenesis of in-stent restenosis and progression of atherosclerosis, which are the main factors responsible for the recurrence of symptoms after endovascular surgery. McDermott et al. [22-28] analyzed this issue earlier, but have not confirmed the relationship between $A B I$ values and the strength of the hand grip.

\section{Conclusions}

1. Endovascular revascularization of the lower limbs not only reduced severity of symptoms of leg ischemia but also improves the scoring in complex activities of patients' daily living.

2. The better nutritional and functional patients' status as well as their greater handgrip strength were associated with a better clinical effect of endovascular surgery, which suggests the need for patients' rehabilitation on each stage of advancement of leg ischemia.

\section{References}

1. Tojek K, Wustrau B, Czerniak B, et al. Body mass index as a biomarker for the evaluation of the "Obesity Paradox" among inpatients. Clin Nutr. 2017 [Epub ahead of print], doi: 10.1016/j.clnu.2017.12.005, indexed in Pubmed: 29291899.

2. Winter JE, Maclnnis RJ, Nowson CA, et al. BMI and all-cause mortality in older adults: a meta-analysis. Am J Clin Nutr. 2014; 99(4): 875-890, doi: 10.3945/ajcn.113.068122, indexed in Pubmed: 24452240.

3. Galyfos G, Geropapas Gl, Kerasidis S, et al. The effect of body mass index on major outcomes after vascular surgery. J Vasc Surg. 2017; 65(4): 1193-1207, doi: 10.1016/j.jvs.2016.09.032, indexed in Pubmed: 27876519

4. Budzyński J, Anaszewicz M. The associations between atrial fibrillation and parameters of nutritional status assessment in the general hospital population - a cross-sectional analysis of medical documentation. Kardiol Pol. 2017; 75(3): 231-239, doi: 10.5603/KP.a2016.0182, indexed in Pubmed: 27995601.

5. Anaszewicz M, Budzyński J. Clinical significance of nutritional status in patients with atrial fibrillation: An overview of current evidence. J Cardiol. 2017; 69(5): 719-730, doi: 10.1016/j.jjcc.2016.06.014, indexed in Pubmed: 27520756

6. Kwon Y, Kim HJ, Park S, et al. Body Mass Index-Related Mortality in Patients with Type 2 Diabetes and Heterogeneity in Obesity Paradox Studies: A Dose-Response Meta-Analysis. PLoS One. 2017; 12(1): e0168247, doi: 10.1371/journal.pone.0168247, indexed in Pubmed: 28046128 .

7. Antonopoulos AS, Oikonomou EK, Antoniades C, et al. From the BMI paradox to the obesity paradox: the obesity-mortality association in coronary heart disease. Obes Rev. 2016; 17(10): 989-1000, doi: 10.1111/obr.12440, indexed in Pubmed: 27405510.

8. Shaparin N, Widyn J, Nair S, et al. Does the obesity paradox apply to early postoperative complications after hip surgery? A retrospective chart review. J Clin Anesth. 2016; 32: 84-91, doi: 10.1016/j.jclinane.2015.12.037, indexed in Pubmed: 27290953

9. Veronese N, Cereda E, Solmi M, et al. Inverse relationship between body mass index and mortality in older nursing home residents: a meta-analysis of 19,538 elderly subjects. Obes Rev. 2015; 16(11): 1001-1015, doi: 10.1111/obr.12309, indexed in Pubmed: 26252230.

10. Spychalska-Zwolińska M, Zwoliński T, Anaszewicz M, et al. The influence of patients' nutritional status on the prevalence, course and treatment outcomes of lower limb ischemia: an overview of current evidence. Int Angiol. 2018; 37(2): 100-111, doi: 10.23736/S03929590.18.03916-0, indexed in Pubmed: 29385791.

11. Cruz-Jentoft AJ, Baeyens JP, Bauer JM, et al. European Working Group on Sarcopenia in Older People. Sarcopenia: European consensus on definition and diagnosis: Report of the European Working Group on Sarcopenia in Older People. Age Ageing. 2010; 39(4): 412-423, doi: 10.1093/ageing/afq034, indexed in Pubmed: 20392703.

12. Santilli V, Bernetti A, Mangone M, et al. Clinical definition of sarcopenia. Clin Cases Miner Bone Metab. 2014; 11(3): 177-180, indexed in Pubmed: 25568649.

13. Locquet M, Beaudart C, Reginster JY, et al. Comparison of the performance of five screening methods for sarcopenia. Clin Epidemiol. 2018; 10: 71-82, doi: 10.2147/CLEP.S148638, indexed in Pubmed: 29343989.

14. Han $P, Y u H, M a Y$, et al. The increased risk of sarcopenia in patients with cardiovascular risk factors in Suburb-Dwelling older Chinese using the AWGS definition. Sci Rep. 2017; 7(1): 9592, doi: 10.1038/s41598017-08488-8, indexed in Pubmed: 28851881

15. Stoever K, Heber A, Eichberg S, et al. Sarcopenia and Predictors of Skeletal Muscle Mass in Elderly Men With and Without Obesity. Gerontol Geriatr Med. 2017; 3: 2333721417713637, doi: 10.1177/2333721417713637, indexed in Pubmed: 28660240.

16. Landry GJ, Esmonde NO, Lewis JR, et al. Objective measurement of lower extremity function and quality of life after surgical revascularization for critical lower extremity ischemia. J Vasc Surg. 2014; 60(1): 136-142, doi: 10.1016/j.jvs.2014.01.067, indexed in Pubmed: 24613190.

17. Yokoyama M, Watanabe T, Otaki Y, et al. Impact of Objective Malnutrition Status on the Clinical Outcomes in Patients With Peripheral Artery Disease Following Endovascular Therapy. Circ J. 2018; 82(3): 847-856, doi: 10.1253/circj.CJ-17-0731, indexed in Pubmed: 29187666.

18. Peacock MR, Farber A, Eslami MH, et al. Hypoalbuminemia Predicts Perioperative Morbidity and Mortality after Infrainguinal Lower Extremity Bypass for Critical Limb Ischemia. Ann Vasc Surg. 2017; 41: 169-175. e4, doi: 10.1016/j.avsg.2016.08.043, indexed in Pubmed: 28242402.

19. Shiraki T, lida O, Takahara M, et al. The Geriatric Nutritional Risk Index is Independently Associated with Prognosis in Patients with Critical Limb Ischemia Following Endovascular Therapy. Eur J Vasc Endovasc 
Surg. 2016; 52(2): 218-224, doi: 10.1016/j.ejvs.2016.05.016, indexed in Pubmed: 27357968

20. Chang SH, Tsai YJ, Huang HL, et al. Clinical predictors of long-term outcomes in patients with critical limb ischemia who have undergone endovascular therapy. Angiology. 2014; 65(4): 315-322, doi: 10.1177/0003319713515544, indexed in Pubmed: 24357434

21. Raval Z, Liu K, Tian Lu, et al. Higher body mass index is associated with more adverse changes in calf muscle characteristics in peripheral arterial disease. J Vasc Surg. 2012; 55(4): 1015-1024, doi: 10.1016/j. jvs.2011.10.105, indexed in Pubmed: 22365177.

22. McDermott MM, Greenland P, Ferrucci L, et al. Lower extremity performance is associated with daily life physical activity in individuals with and without peripheral arterial disease. J Am Geriatr Soc. 2002 50(2): 247-255, indexed in Pubmed: 12028205

23. McDermott MM, Greenland P, Liu K, et al. The ankle brachial index is associated with leg function and physical activity: the Walking and Leg Circulation Study. Ann Intern Med. 2002; 136(12): 873-883, indexed in Pubmed: 12069561.

24. McDermott MM, Guralnik JM, Tian Lu, et al. Associations of borderline and low normal ankle-brachial index values with functional decline a 5-year follow-up: the WALCS (Walking and Leg Circulation Study). J Am Coll Cardiol. 2009; 53(12): 1056-1062, doi: 10.1016/j.jacc.2008.09.063 indexed in Pubmed: 19298919.

25. Ruo B, Liu K, Tian Lu, et al. Functional decline in peripheral arterial disease: associations with the ankle brachial index and leg symptoms. JAMA. 2004; 292(4): 453-461, doi: 10.1001/jama.292.4.453 indexed in Pubmed: 15280343

26. McDermott MM, Tian Lu, Ferrucci L, et al. Associations between lower extremity ischemia, upper and lower extremity strength, and functional impairment with peripheral arterial disease J Am Geriatr Soc 2008; 56(4): 724-729, doi: 10.1111/j.1532-5415.2008.01633.x, indexed in Pubmed: 18284536.

27. McDermott MM, Tian Lu, Liu K, et al. Prognostic value of functional performance for mortality in patients with peripheral artery disease. J Am
Coll Cardiol. 2008; 51(15): 1482-1489, doi: 10.1016/j.jacc.2007.12.034, indexed in Pubmed: 18402904

28. McDermott MM. Lower extremity manifestations of peripheral artery disease: the pathophysiologic and functional implications of leg ischemia. Circ Res. 2015; 116(9): 1540-1550, doi: 10.1161/CIRCRESAHA.114.303517, indexed in Pubmed: 25908727.

29. Mazari F, Khan JA, Carradice D, et al. Economic analysis of a randomized trial of percutaneous angioplasty, supervised exercise or combined treatment for intermittent claudication due to femoropopliteal arterial disease. British Journal of Surgery. 2013; 100(9): 1172-1179, doi: 10.1002/bjs.9200

30. Malgor RD, Alahdab F, Alalahdab F, et al. A systematic review of treatment of intermittent claudication in the lower extremities. J Vasc Surg. 2015; 61(3 Suppl): 54S-73S, doi: 10.1016/j.jvs.2014.12.007, indexed in Pubmed: 25721067.

31. Olin JW, White CJ, Armstrong EJ, et al. Peripheral Artery Disease: Evolving Role of Exercise, Medical Therapy, and Endovascular Options. J Am Coll Cardiol. 2016; 67(11): 1338-1357, doi: 10.1016/j. jacc.2015.12.049, indexed in Pubmed: 26988957.

32. Reynolds MR, Apruzzese P, Galper BZ, et al. Cost-effectiveness of supervised exercise, stenting, and optimal medical care for claudication: results from the Claudication: Exercise Versus Endoluminal Revascularization (CLEVER) trial. J Am Heart Assoc. 2014; 3(6): 001233, doi: 10.1161/JAHA.114.001233, indexed in Pubmed: 25389284.

33. Stepaniak U, Micek A, Waśkiewicz A, et al. Prevalence of general and abdominal obesity and overweight among adults in Poland. Results of the WOBASZ II study (2013-2014) and comparison with the WOBASZ study (2003-2005). Pol Arch Med Wewn. 2016; 126(9): 662-671, doi: 10.20452/pamw.3499, indexed in Pubmed: 27535012.

34. Morisaki K, Yamaoka T, Iwasa K, et al. Influence of frailty on treatment outcomes after revascularization in patients with critical limb ischemia. J Vasc Surg. 2017; 66(6): 1758-1764, doi: 10.1016/j.jvs.2017.04.048, indexed in Pubmed: 28647199. 